\title{
Survei Minat dan Motivasi Mahasiswa Terhadap Ekstrakurikuler Futsal
}

\author{
Sulikan \\ Program Studi Pendidikan Jasmani Kesehatan dan Rekreasi IKIP Budi Utomo \\ Jalan Simpang Arjuno 14 B Malang \\ Sulikan_ms@yahoo.co.id
}

\begin{abstract}
Interest from someone is influenced by many factors, namely internally and externally. Motivation is one of the thing which is coming from inside. The goal of the research is to know how far the university students' interest and motivation are in joining with extracurricular of futsal. The study was done through survey with two free variables, interest and motivation, while the instrument used to collect data were questionaires and documentation. Based on the analysis, it was found that the students' responses 'strongly agree' in terms of their interest are 44.34\%, 'agree' 35.97\%, while the rest as their responses 'disagree' and 'strongly disagree' $16.74 \%$ and $2.94 \%$ respectively. Moreover, the students' responses 'strongly agree' in terms of their motivation are 46.66\%, 'agree' 35.53\%, while the rest as their responses 'disagree' and 'strongly disagree' $14.79 \%$ and $3.01 \%$ respectively. Of the result, it can be concluded that the university students had high category of both interst and motivation. Therefore, it was suggested that they could defend their godd interest and motivation.
\end{abstract}

Keywords: interest, motivation, students, extracurricular, futsal.

Salah satu komponen pendidikan yang wajib diajarkan di lapangan yaitu mata ekstrakurikuler futsal. Hal ini dikarenakan pendidikan jasmani memiliki peran sangat strategis dalam pembentukan manusia seutuhnya. Pendidikan jasmani pada hakikatnya adalah proses pendidikan yang memanfaaatkan aktifitas fisik untuk menghasilkan perubahan holistik dalam kualitas individu, baik dalam hal fisik, mental, serta emosional diarahkan untuk mendorong, membimbing, mengembangkan, dan membina jasmani dan rohani. Mahamahamahamahasiswa dan lingkungan hidupnya agar tumbuh secara harmonis dan optimal sehingga mampu melaksanakan tugas bagi dirinya sendiri maupun bagi bangsa dan negara (Rosdiani 2012:41). Secara umum orang memahami futsal merupakan salah satu aktivitas jasmani yang dilakukan oleh orang, sekelompok orang dengan tujuan untuk menciptakan kebugaran jasmani. Aktivitas futsal dilakukan oleh semua orang tanpa melihat perbedaan usia. Pengalaman belajar tidak hanya didapat saat dalam proses belajar mengajar saja, tetapi bisa didapatkan pada kegiatan diluar jam pelajaran yang biasa disebut dengan Ekstrakurikuler. Menurut Wahdjosoemidjo (2002:215) menjelaskan bahwa ekstrakulikuler adalah kegiatan yang diselenggarakan diluar jam pelajaran yang tercantum dalam susunan progam sesuai dengan keadaan dan kebutuhan prodi PJKR (Wahdjosoemidjo, 2002:215).

Kegiatan ektrakurikuler berfungsi sebagai wahana untuk menampung, menyalurkan, dan membina minat serta kegemaran maha maha mahasiswa dalam berbagai bidang. Dalam hal membina minat serta kegemaran mahasiswa dalam berbagai bidang, salah satu bidang yang dikembangkan melalui kegiatan ekstrakurikuler di Prodi PJKR adalah futsal futsal, hampir setiap hari lapangan bola basket yang digunakan sebagai lapangan futsal dipenuhi oleh para mahasiswa yang mengikuti kegiatan ekstrakurikuler baik sore maupun malam hari, yang lebih nyata ternyata mahasiswa yang berasal dari wilayah timur indonesia yang lebih banyak mengikuti ekstrakurikuler futsal futsal, sedangkan yang mengikuti kegiatan ekstrakurikuler selain cabang futsal futsal tidak banyak yang berminat dan termotivasi untuk mengikuti ekstrakurikuler. Berdasarkan realita yang seperti itulah peneliti ingin mencari apa yang menyebabkan mahasiswa lebih menyukai ekstrakurikuler futsal dibandingkan dengan futsal sepak bola, bola basket, bola voli dan futsal lainnya. 
Salah satu kegiatan futsal yang saat ini sedang populer adalah kegiatan futsal dengan adanya wadah yang mampu menghimpun berbagai lapisan, jenjang,yang ada di Prodi Pendidikan Jasmani Kesehatan Dan Rekreasi. Futsal Futsal adalah pengembangan dari permainan sepakbola. Dimana permainan futsal ini dimainkan didalam ruangan yang terdiri dari 2 tim yang masing-masing tim terdiri dari 5 orang (Sabda Halim. 2009:9). Dalam kegiatan futsal futsal, selain aspek kognitif yaitu tentang pemahaman terhadap peraturan futsal futsal, penguasaan ketrampilan bermain futsal, penguasaan tentang perwasitan futsal futsal mahasiswa juga belajar aspek afektif, yaitu halhal yang berkaitan dengan perilaku dan sikap. Dari segi afektif ini banyak tujuan dan manfaat yang diharapkan dapat tercapai oleh mahasiswa dalam mengikuti kegiatan futsal, diantaranya sikap sportif, memiliki rasa tanggung jawab, adanya keinginan bekerjasama, cepat mengambil keputusan, menghargai lawan, bermain, dan lain sebagainya.

Dalam penelitian ini, penulis mengangkat judul" Survei minat dan motivasi mahasiswa terhadap ekstrakurikuler futsal. Alasan di balik pengambilan judul di atas di karenakan bahwa futsal menjadi futsal yang sangat pesat perkembangannya di masyarakat baik di kotakota besar sampai dipedesaan, hal ini bisa dilihat makin banyaknya orang membangun lapangan futsal untuk dijadikan usaha yang menjanjikan sehingga futsal sangat populer baik dikalangan anak-anak, remaja, sampai dengan orangtua bermain futsal.

Berdasarkan uraian dari latar belakang diatas maka peneliti merumuskan suatu permasalahan seberapa besar minat dan motivasi mahasiswa dalam mengikuti ekstrakulikuler. Tujuan penelitian ini adalah untuk mengetahui seberapa besar minat dan motivasi mahasiswa dalam mengikuti ekstrakurikuler futsal futsal.

\section{METODE}

Dalam penelitian ini metode yang digunakan penulis adalah metode survei. Metode ini dipilih dikarenakan sangat efektif untuk mengumpulkan data secara jelas dan akurat. Hal ini disebabkan peneliti terjun secara langsung di lapangan untuk melihat kondisi, masalah, maupun faktor-faktor lain yang dibutuhkan untuk menjawab permasalahan yang sudah di angkat dalam penelitian. Sehingga peneliti dapat memperoleh data yang akurat secara cepat dan sesuai dengan rumusan masalah. Dalam metode survei, peneliti mengambil populasi adalah seluruh mahamahasiswa yang mengikuti ekstrakurikuler futal di prodi PJKR yang berjumlah 50 mahamahamahasiswa untuk dijadikan total sampling. Instrumen adalah alat atau fasilitas yang digunakan peneliti agar dapat mengolah data lebih mudah dan bisa menarik sebuah hasil yang diinginkan,dalam arti lebih cermat, lengkap dan, dan sistematis sehingga lebih mudah diolah (Arikunto 2006:160). Variasi jenis instrumen dalam penelitian adalah: Angket, Cheklist, Pedoman Wawancara, Pedoman Pengamatan. Dalam penelitian ini instrumen yang di gunakan adalah angket atau kuisioner, kuisoner sendiri merupakan pernyataan tertulis yang digunakan untuk memperoleh informasi dari reponden atau sampel tentang laporan dirinya (Arikunto 2006:151).

Untuk merangcang sebuah instrumen maka di perlukan langkah langkah awal yaitu membuat kisi kisi instrumen, merancang kisi kisi instrumen dimulai dari menenntukan variabel, kemudian memecahnya menjadi indikator, sub variabel dan membuat pernyataan dari instrumen tersebut. Berikut adalah kisi - kisi instrumen

Tabel 1. Kisi-kisi Instrumen

\begin{tabular}{|c|c|c|c|}
\hline Variabel & Indikator & No Soal & Jumlah \\
\hline $\begin{array}{l}\text { *Minat mahamahasiswa terhadap } \\
\text { ekstrakuurikuler futsal }\end{array}$ & $\begin{array}{l}\text { Sikap terhadap pembina/ } \\
\text { pelatih }\end{array}$ & $1,2,3,4,5,6,7,8,9$ & 9 soal \\
\hline \multirow{3}{*}{$\begin{array}{l}\text { *Motivasi mahamahasiswa terhadap } \\
\text { ekstrakurikuler futsal }\end{array}$} & Perasaan senang & $10,11,12,13,14,15,16,17$ & 8 soal \\
\hline & Kemauan & $18,19,20,21,22,23,24,25,26$ & 9 soal \\
\hline & $\begin{array}{l}\text { Sosial (sikap peduli } \\
\text { terhadap sesama) }\end{array}$ & $27,28,29,30$ & 4 soal \\
\hline
\end{tabular}


Langkah-langkah dalam melakukukan uji coba Validitas antara lain sebagai berikut: Angket diujicobakan pada 50 mahasiswa, b). memberi skor pada setiap pernyataan dengan rincian sebagai berikut: Untuk jawaban Sangat Setuju di beri nilai 4, Jawaban Setuju diberi nilai 3,Jawaban Tidak Setuju diberi nilai 2, Jawaban Sangat Tidak Setuju diberi nilai 1, memasukan data hasil ujicoba kedalam sebuah tabel,melakukan uji Rank Spearman dengan program SPSS, Uji Coba Reliabilitas merujuk pada suatu pengertian bahwa sebuah instrumen dapat dipercaya karena instrumen tersebut sudah baik. Instrumen yang baik tidak akan mengarahkan responden untuk memilih jawaban-jawaban tertentu. Instrumen yang reliabel maka akan menghasilkan datadata yang akan dapat dipercaya. Reliabel artinya dapat dipercaya, jadi dapat diandalkan.Ujicoba reliabilitas dilakukan dengan Uji Reliabilitas Alpha Cronbach's yang dihitung dengan memanfaatkan program SPSS yaitu aplikasi perangkat lunak yang ada pada komputer.

Langkah-langkah dalam melakukukan uji coba Reliabilitas dengan Uji Reliabilitas Apha Cronbach's antara lain sebagai berikut: Angket diujicobakan pada 50 mahasiswa, memberi skor pada setiap pernyataan dengan rincian sebagai berikut : untuk jawaban Sangat Setuju di beri nilai 4, jawaban Setuju diberi nilai 3 Jawaban Tidak Setuju diberi nilai 2, jawaban Sangat Tidak Setuju diberi nilai 1, memasukan data hasil ujicoba kedalam sebuah tabel, melakukan ujicoba Reliabilitas dengan Uji Relibitas Alpha Cronbach's dengan program SPSS. Pengumpulan dan pengolahan data dengan menggunakan kuisioner dan dokumentasi berupa data mahasiswa. Analisa data menggunakan rumus :

$$
P=(f \div n) \times 100
$$

Ket:

$\mathrm{P}=$ Presentase jawaban

$\mathrm{F}=$ Frekuensi (jumlah mahasiswa yang menjawab)

$\mathrm{N}=$ Jumlah Frekuensi keseluruhan mahasiswa
Tabel 2. Kriteria Presentase Jawaban

\begin{tabular}{ccc}
\hline $\begin{array}{c}\mathrm{P}=\text { Pre- } \\
\text { sentase } \\
\text { jawaban }\end{array}$ & $\begin{array}{c}\mathrm{F}=\text { Frekuensi } \\
\text { (jumlah ma- } \\
\text { hasiswa yang } \\
\text { menjawab) }\end{array}$ & $\begin{array}{c}\mathrm{N}=\text { Jumlah Frekuensi } \\
\text { keseluruhan maha- } \\
\text { siswa }\end{array}$ \\
\hline
\end{tabular}

Hasil perhitungan nantinya akan diasjikan dalam bentuk tabel dan diagram. Langkahlangkah dalam pengolahan data antara lain sebagai berikut: menghitung jumlah dari masing masing gradasi atau peringkat ( Sangat Setuju, Setuju, Tidak Setuju, Sangat Tidak Setuju) yang dipilih reponden dari setiap soal, menentunkan nilai nilai dari masing-masing gradasi dari setiap soal, memasukan data hasil perhitungan setiap soal kedalam sebuah tabel perhitungan, menghitung nilai presentase dari masing masing gradasi di setiap soal, menentukan nilai presentase indikator dengan menghitung rata rata dari nilai gradasi setiap soal, menentukan nilai presentaseSubVariabeldenganmenghitung rata rata dari nilai indikato, menentukan nilai Variabel dengan menghitung rata rata dari nilai Sub Variabel, hasil per indikator akan di tampilkan dalam bentuk diagram, hasil per sub variabel akan ditampilkan dalam bentuk diagram, dan hasil variabel akan ditampilkan dalam bentuk diagram.

\section{HASIL DAN PEMBAHASAN}

\section{Minat mahasiswa}

Dalam variabel minat terdapat dua indikator yaitu sikap terhadap pembina dan perasaan senang, dari dua indikator tersebut, selanjutnya saya akan menjabarkan bentuk perhitungannya yang saya sajikan dalam bentuk tabel berikut hasil perhitungannya. Sikap Terhadap Pembina: Dalam indikator sikap terhadap pembina terdapat 9 butir pernyataan yang ada di dalam angket penelitian yaitu pernyataan nomor $1,2,3,4,5,6,7,8,9$ yang kemudian di setiap pernyataannya dihitung dengan presentase. 
| Sulikan, Survei Minat dan Motivasi Mahasiswa ...

Tabel 3. Hasil Perhitungan Indikator Sikap Terhadap Pembina

\begin{tabular}{|c|c|c|c|c|c|}
\hline \multicolumn{6}{|c|}{ SIKAP TERHADAP PEMBINA/ PELATIH } \\
\hline \multirow{2}{*}{ No } & \multirow{2}{*}{ PERNYATAAN } & \multicolumn{4}{|c|}{ Jumlah Pemilih dan Presentase } \\
\hline & & SS & $S$ & TS & STS \\
\hline \multirow[t]{2}{*}{1} & Saya bersedia menerima hukuman apabila & 20 & 22 & 6 & 1 \\
\hline & futsal & $40,81 \%$ & $44,89 \%$ & $12,24 \%$ & $2,04 \%$ \\
\hline \multirow[t]{2}{*}{2} & Saya selalu memperhatikan pembina, ke- & 26 & 13 & 7 & 2 \\
\hline & $\begin{array}{l}\text { tika pembina sedang memberikan penjeia- } \\
\text { san tentang teknik futsal futsal. }\end{array}$ & $54,16 \%$ & $28,08 \%$ & $14,58 \%$ & $4,16 \%$ \\
\hline \multirow[t]{2}{*}{3} & Saya merasa lebih semangat karena pelatih & 19 & 16 & 12 & 1 \\
\hline & sangat baik & $39,58 \%$ & $33,33 \%$ & $25 \%$ & $20,83 \%$ \\
\hline 4 & $\begin{array}{l}\text { Saya ingin meningkatkan kegiatan per- } \\
\text { mainan futsal futsal di Prodi PJKR. }\end{array}$ & $\begin{array}{c}14 \\
28,57 \%\end{array}$ & $\begin{array}{c}21 \\
42,85 \%\end{array}$ & $\begin{array}{c}10 \\
20,40 \%\end{array}$ & $\begin{array}{c}4 \\
8,16 \%\end{array}$ \\
\hline \multirow[t]{2}{*}{5} & $\begin{array}{l}\text { Saya ingin meningkatkan prestasi pada ca- } \\
\text { bang futsal futsal. }\end{array}$ & 19 & 16 & 11 & 3 \\
\hline & & $38,77 \%$ & $32,65 \%$ & $22,44 \%$ & $6,12 \%$ \\
\hline \multirow[t]{2}{*}{6} & Teman-teman dan para pembina menun- & 17 & 18 & 9 & 4 \\
\hline & $\begin{array}{l}\text { jukkan apresiasi yang besar dalam per- } \\
\text { mainan futsal. }\end{array}$ & $35,41 \%$ & $37,5 \%$ & $18,75 \%$ & $8,33 \%$ \\
\hline \multirow[t]{2}{*}{7} & Pelatih memberikan penghargaan pada & 4 & 13 & 10 & 4 \\
\hline & & $12,90 \%$ & $41,93 \%$ & $32,25 \%$ & $12,90 \%$ \\
\hline \multirow[t]{2}{*}{8} & Pihak prodi akan memberikan perng- & 20 & 16 & 12 & 0 \\
\hline & $\begin{array}{l}\text { hargaan apabila tim futsal kami berhasil } \\
\text { meraih juara. }\end{array}$ & $41,66 \%$ & $33,33 \%$ & $25 \%$ & $0 \%$ \\
\hline \multirow{2}{*}{9} & Perlengkapan yang dibutuhkan dalam & 23 & 17 & 10 & 0 \\
\hline & $\begin{array}{l}\text { permainan futsal di prodi PJKR sangat } \\
\text { lengkap. }\end{array}$ & $46 \%$ & $34 \%$ & $20 \%$ & $0 \%$ \\
\hline
\end{tabular}

Tabel 4. Hasil Rata Rata Indikator Sikap Terhadap Pembina atau pelatih

\begin{tabular}{|c|c|c|c|}
\hline \multicolumn{4}{|c|}{ Rata-Rata Presentase dari Indikator Sikap Terhadap Pembina atau pelatih } \\
\hline $\begin{array}{c}\text { Sangat Setuju/Sangat } \\
\text { Tinggi }\end{array}$ & Setuju/Tinggi & Tidak Setuju/Rendah & $\begin{array}{c}\text { Sangat Tidak Tetuju/Sangat } \\
\text { Rendah }\end{array}$ \\
\hline $37,34 \%$ & $36,39 \%$ & $21,18 \%$ & $4,868 \%$ \\
\hline
\end{tabular}

Dari hasil penghitungan dapat disimpulakan bahwa sikap mahamahasiswa terhadap pembina atau pelatih menunjukan sikap sangat setuju/ sangat tinggi $37,34 \%$, sikap setuju/ tinggi sebesar $36,39 \%$, sikap tidak setuju/ rendah sebesar $21,18 \%$, dan sikap sangat tidak setuju/ sangat rendah sebesar $4,868 \%$, sehingga dapat disimpulkan bahwa sikap mahamahasiswa terhadap pembina/ pelatih futsal sangat tinggi.
Dengan sikap yang sangat tinggi menunjukkan minat mahamahasiswa terhadap ekstrakurikuler futsal sangat tinggi.

Perasaan Senang : Dalam indikator perasaan senang terdapat 8 butir pernyataan yang ada di dalam angket penelitian yaitu pernyataan nomor $10,11,12,13,14,15,17$, yang kemudian di setiap pernyataan nya di hitung dengan presentase. 
Tabel 5. Hasil Perhitungan Indikator Perasaan Senang

\begin{tabular}{|c|c|c|c|c|c|}
\hline \multicolumn{6}{|c|}{ PERASAAN SENANG } \\
\hline \multirow{2}{*}{ No } & \multirow{2}{*}{ PERNYATAAN } & \multicolumn{4}{|c|}{ Jumlah Pemilih dan Presentase } \\
\hline & & SS & $S$ & TS & STS \\
\hline \multirow[t]{2}{*}{10} & $\begin{array}{l}\text { Saat melakukan pemanasan kemudian pembina } \\
\text { tidak memperhatikan sava maka sava tetap }\end{array}$ & 33 & 14 & 2 & 0 \\
\hline & melakukan pemanasan & $67,34 \%$ & $28,57 \%$ & $4,081 \%$ & $0 \%$ \\
\hline \multirow[t]{2}{*}{11} & Saya bersikap jujur ketika saya melanggar pera- & 27 & 21 & 1 & 0 \\
\hline & & $55,10 \%$ & $42,85 \%$ & $2,04 \%$ & $0 \%$ \\
\hline \multirow[t]{2}{*}{12} & Bagi saya setelah melakukan ekstrakurikuler & 28 & 14 & 7 & 0 \\
\hline & suasana belajar saya di matakuliah lain. & $57,14 \%$ & $28,57 \%$ & $14,28 \%$ & $0 \%$ \\
\hline \multirow[t]{2}{*}{13} & $\begin{array}{l}\text { Permainan dalam futsal mempengaruhi suasana } \\
\text { kelas menjadi lebih ceria saat mengikuti perku- }\end{array}$ & 22 & 20 & 7 & 0 \\
\hline & liahan lain. & $44,89 \%$ & $40,81 \%$ & $14,28 \%$ & $0 \%$ \\
\hline 14 & $\begin{array}{l}\text { Saya selalu ingin menjadi yang terbaik dalam } \\
\text { setiap ekstrakurikuler futsal }\end{array}$ & 19 & 19 & 9 & 2 \\
\hline \multirow[t]{2}{*}{15} & $\begin{array}{l}\text { Ekstrakurikuler futsal juga saya jadikan latihan } \\
\text { tambahan untuk mengasah kemampuan saya }\end{array}$ & 22 & 19 & 8 & 0 \\
\hline & ketika ada perlombaan antar lapangan & $44,89 \%$ & $38,77 \%$ & $16,32 \%$ & $0 \%$ \\
\hline \multirow[t]{2}{*}{16} & Ekstrakurikuler futsal berperan penting dalam & 27 & 16 & 4 & 2 \\
\hline & dan sehat & $55,10 \%$ & $32,65 \%$ & $8,163 \%$ & $4,081 \%$ \\
\hline \multirow[t]{2}{*}{17} & Ekstrakurikuler futsal berperan penting dalam & 27 & 16 & 4 & 2 \\
\hline & $\begin{array}{l}\text { pembentukan generasi indonesia yang muda } \\
\text { dan sehat }\end{array}$ & $55,10 \%$ & $32,65 \%$ & $8,163 \%$ & $4,081 \%$ \\
\hline
\end{tabular}

Tabel 6. Hasil Rata-Rata Indikator Perasaan Senang

\begin{tabular}{cccc}
\hline \multicolumn{3}{c}{ Rata-Rata Presentase dari Indikator Perasaan Senang } \\
\hline $\begin{array}{c}\text { Sangat Setuju/Sangat } \\
\text { Tinggi }\end{array}$ & Setuju/Tinggi & Tidak Setuju/Rendah & Sangat Tidak Setuju/Sangat \\
$51,13 \%$ & $35,54 \%$ & $12,29 \%$ & Rendah \\
\hline
\end{tabular}

Dari hasil penghitungan indikator menunjukan hasil bahwa mahamahasiswa mempunyai perasaan senang yang sangat tinggi terhadap ekstrakurikuler futsal dengan $51,13 \%$, perasaan tinggi/ setuju terhadap ekstrakurikuler futsal, perasaan senang rendah terhadap ekstrakurikuler futsal 12, $29 \%$ dan perasaan tidak senang terhadap ekstrakurikuler futsal Cuma
1,020 \%, kesimpulannya bahwa rata-rata mahasiswa mempunyai persaan sangat senang saat mengikuti ekstrakurikuler futsal.

Motivasi Mahamahasiswa: dalam variabel motivasi terdapat dua indikator yaitu kemauan dan sosial sikap terhadap sesama sajikan dalam bentuk tabel berikut hasil perhitungannya. 
Tabel 7. Hasil Perhitungan Indikator Kemauan

\begin{tabular}{|c|c|c|c|c|c|}
\hline \multicolumn{6}{|c|}{ KEMAUAN } \\
\hline \multirow{2}{*}{ No } & \multirow{2}{*}{ PERNYATAAN } & \multicolumn{4}{|c|}{ Jumlah Pemilih dan Presentase } \\
\hline & & SS & $\mathrm{S}$ & TS & STS \\
\hline \multirow{2}{*}{18} & \multirow{2}{*}{$\begin{array}{l}\text { Saat pembina/ pelatih menerangkani tentang } \\
\text { futsal saya sangat antusias memperhatikan- } \\
\text { nya }\end{array}$} & 41 & 9 & 0 & \multirow{2}{*}{$\begin{array}{c}0 \\
0 \%\end{array}$} \\
\hline & & $82 \%$ & $18 \%$ & $0 \%$ & \\
\hline \multirow{2}{*}{19} & \multirow{2}{*}{$\begin{array}{l}\text { Ketika sedang melakukan pemanasan saya } \\
\text { melakukannya sedang sungguh-sungguh }\end{array}$} & 21 & 23 & 5 & 0 \\
\hline & & $42,85 \%$ & $46,93 \%$ & $10,20 \%$ & $0 \%$ \\
\hline \multirow[b]{2}{*}{20} & \multirow{2}{*}{$\begin{array}{l}\text { Selalu menghormati pembina/ pelatih ketika } \\
\text { dilapangan dan tidak membantah perintah- } \\
\text { nya selama itu bertujuan untuk menyehatkan } \\
\text { kita. }\end{array}$} & 19 & 21 & 5 & 3 \\
\hline & & $39,58 \%$ & 43,75 & $10,41 \%$ & $6,25 \%$ \\
\hline \multirow{2}{*}{21} & \multirow{2}{*}{$\begin{array}{l}\text { Saya akan menegur teman saya Ketika teman } \\
\text { saya ada yang mengajak bercanda ketika } \\
\text { melakukan pemanasan }\end{array}$} & 20 & 15 & 14 & 0 \\
\hline & & $40,81 \%$ & $30,61 \%$ & $28,57 \%$ & $0 \%$ \\
\hline \multirow{2}{*}{22} & \multirow{2}{*}{$\begin{array}{l}\text { Selalu berusaha datang tepat waktu saat Ek- } \\
\text { strakurikuler futsal }\end{array}$} & 20 & 12 & 10 & 6 \\
\hline & & $41,66 \%$ & $25 \%$ & $20,83 \%$ & $12,5 \%$ \\
\hline \multirow{2}{*}{23} & \multirow{2}{*}{$\begin{array}{l}\text { Saat di rumah saya sering mempelajari atau } \\
\text { melatih gerakan-gerakan dalam ekstrakuri- } \\
\text { kuler futsal yang di ajarkan pembina/ pelatih } \\
\text { di lapangan. }\end{array}$} & 21 & 17 & 9 & 2 \\
\hline & & $42,85 \%$ & $34,69 \%$ & $18,36 \%$ & $4,081 \%$ \\
\hline \multirow{2}{*}{24} & \multirow{2}{*}{$\begin{array}{l}\text { Teman teman saya berperan penting dalam } \\
\text { peningkatan kemampuan saya saat aktivitas } \\
\text { di lapangan }\end{array}$} & 19 & 24 & 6 & 0 \\
\hline & & $38,77 \%$ & $48,97 \%$ & $12,24 \%$ & $0 \%$ \\
\hline \multirow{2}{*}{25} & \multirow{2}{*}{$\begin{array}{l}\text { Ekstrakurikuler futsal juga saya jadikan lati- } \\
\text { han tambahan untuk mengasah kemampuan } \\
\text { saya ketika ada perlombaan antar lapangan }\end{array}$} & 19 & 18 & 10 & 2 \\
\hline & & $38,77 \%$ & $36,73 \%$ & $20,40 \%$ & $4,081 \%$ \\
\hline \multirow{2}{*}{26} & \multirow{2}{*}{$\begin{array}{l}\text { Saling membantu untuk kemenangan sebuah } \\
\text { permainan }\end{array}$} & 21 & 24 & 4 & 0 \\
\hline & & $42,85 \%$ & $48,97 \%$ & $8,163 \%$ & $0 \%$ \\
\hline
\end{tabular}

Dengan hasil jawaban tersebut maka akan di dapatkan hasil jawaban dari indikator kemauan dengan menghitung rata rata dari ke 9 butir pernyataan tersebut. menunjukkan kemauan dalam mengikuti ektrakurikuler sangat rendah. Dengan demikian dapat disimpulkan bahwa rata-rata kemauan mahasiswa dalam mengikuti ekstrakurkuler sangat tinggi.

Tabel 9. Hasil Perhitungan Indikator Kemauan

\begin{tabular}{cccc}
\hline & \multicolumn{3}{c}{ Rata-Rata Presentase dari Indikator kemauan } \\
\hline $\begin{array}{c}\text { Sangat Setuju/Sangat } \\
\text { Tinggi }\end{array}$ & Setuju/Tinggi & Tidak Setuju/Rendah & Sangat Tidak Setuju/Sangat \\
$45,57 \%$ & $37,07 \%$ & $14,35 \%$ & Rendah \\
& & $2,990 \%$ \\
\hline
\end{tabular}

Dari penghitungan menunjukkan indikator bahwa kemauan mahasiswa untuk mengikuti ekstrakurikuler futsal sangat tinggi dengan ratarata $45,57 \%, 37,07 \%$ menunjukkan kemauan tinggi, $14,35 \%$ menunjukkan kemauan mengikuti ekstrakurikuler futsal rendah, dan 2,99\%

\section{Sikap Sosial}

Dalam indikator sikap sosial terdapat 4 butir pernyataan yang terdapat didalam angket yaitu pernyataan nomor 27,28,29,30 yang kemudian akan dihitung dengan presentase setiap pernyataannya. 
Tabel 10. Hasil Perhitungan Indikator Sosial

\begin{tabular}{clcccc}
\hline \multicolumn{5}{c}{ SOSIAL (SIKAP PEDULI TERHADAP SESAMA) } \\
\hline \multirow{2}{*}{ No } & \multicolumn{1}{c}{ PERNYATAAN } & SS & S & TS & STS \\
\cline { 2 - 5 } 27 & $\begin{array}{l}\text { Saya bersedia jika di tunjuk guru untuk } \\
\text { memimpin pemanasan dalam mata ekstr- }\end{array}$ & 23 & 16 & 10 & 0 \\
akurikuler futsal & $46,93 \%$ & $32,65 \%$ & 20,40 & $0 \%$ \\
28 & $\begin{array}{l}\text { Saya merasa gerakan gerakan dalam Ekstr- } \\
\text { akurikuler futsal membuat saya menjadi segar } \\
\text { dan menyehatkan }\end{array}$ & 21 & 19 & 7 & 3 \\
29 & $\begin{array}{l}\text { Saya bersemangat ketika melakukan aktivitas } \\
\text { Jasmani karena teman teman saya lucu-lucu }\end{array}$ & 31 & $38 \%$ & $14 \%$ & $0 \%$ \\
\multirow{2}{*}{30} & $\begin{array}{l}\text { Ketika saya gagal melakukan gerakan yang } \\
\text { sulit dalam aktivitas jasmani saya tidak akan } \\
\text { putus asa. }\end{array}$ & 19 & 12 & 6 & 0 \\
\hline
\end{tabular}

Dari jawaban tersebut maka akan di dapatkan hasil jawaban dari indikator sosial dengan menghitung rata rata dari ke 5 butir pernyataan tersebut sebagai berikut :

Tabel 11. Hasil Rata-Rata Indikator Sosial

\begin{tabular}{cccc}
\hline \multicolumn{3}{c}{ Rata-Rata Presentase dari Indikator Sosial } \\
\hline Sangat & Setuju/ & $\begin{array}{c}\text { Tidak } \\
\text { Setuju/ } \\
\begin{array}{c}\text { Sangat } \\
\text { Tinggi }\end{array}\end{array}$ & $\begin{array}{c}\text { Sangat } \\
\text { Tidak Setu- } \\
\text { ju/Sangat } \\
\text { Rendah }\end{array}$ \\
\hline $47,74 \%$ & $33,98 \%$ & $15,23 \%$ & $3,03 \%$ \\
\hline
\end{tabular}

Dari penghitungan menunjukkan bahwa sikap sosial sesama teman para mahamahasiswa dalam mengikuti ekstrakurikuler futsal sangat tinggi dengan rata-rata $47,74 \%, 33,98 \%$ menunjukkan sikap sosial tinggi sesama teman, dan 15,23\% menunjukkan sikap sosial rendah, serta 3,03\% menunjukkan sikap sosial sangat rendah. Kesimpulannya bahwa rata-rata para mahamahasiswayangmengikutiekstrakurikuler futsal mempunyai rasa sosial yang sangat tinggi terhadap sesama teman.

Tabel. 12. Hasil perhitungan variabel motivasi

\begin{tabular}{ccccc}
\hline & \multicolumn{2}{c}{ KEMAUAN } & \multicolumn{2}{c}{$\begin{array}{c}\text { SOSIAL SIKAP } \\
\text { PEDULI TERHA- } \\
\text { DAP SESAMA }\end{array}$} \\
MOTIVASI & & & \multicolumn{2}{c}{ DS } \\
MAHA- & SS & $45,57 \%$ & SS & $47,74 \%$ \\
SISWA & S & $37,07 \%$ & S & $33,98 \%$ \\
& TS & $14,35 \%$ & TS & $15,23 \%$ \\
& STS & $2,99 \%$ & STS & $3,03 \%$ \\
\hline
\end{tabular}

Dari tabel di atas selanjutnya dihitung rata dari motivasi mahasiswa dengan perhitungan sebagai berikut

Tabel. 13, rata rata motivasi mahasiswa terhadap ekstrakurikuler futsal

Rata-Rata motivasi mahasiswa terhadap ekstrakurikuler futsal

\begin{tabular}{cccc}
\hline $\begin{array}{c}\text { Sangat } \\
\text { Setuju/ } \\
\text { Sangat } \\
\text { Tinggi }\end{array}$ & $\begin{array}{c}\text { Setuju/ } \\
\text { Tinggi }\end{array}$ & $\begin{array}{c}\text { Tidak } \\
\text { Setuju/ } \\
\text { Rendah }\end{array}$ & $\begin{array}{c}\text { Sangat } \\
\text { Tidak Setu- } \\
\text { ju/Sangat } \\
\text { Rendah }\end{array}$ \\
\hline $46,66 \%$ & $35,53 \%$ & $14,79 \%$ & $3,01 \%$ \\
\hline
\end{tabular}

Rata-rata motivasi mahasiswa terhadap ekstrakurikuler menunjukkan bahwa kemauan dan rasa sosial sesama teman sangat tinggi dengan rata-rata $46,66 \%$, sedangkan yang menunjukkan kemauan dan rasa sosial sesama teman tinggi dengan 35,53 \%, motivasi cukup rendah $14,79 \%$, serta 3,01 \% menunjukkan kemauan dan sikap sosioal terhadap sesama teman sangat rendah. Kesimpulannya bahwa motivas mahasiswa dengan indikator kemauan dan sikap sosial terhadap teman sangat tinggi dalam mengikuti ekstrakurikuler futsal.

\section{KESIMPULAN DAN SARAN}

Bahwa sikap mahamahasiswa terhadap pembina/ pelatih futsal sangat tinggi. Dengan sikap yang sangat tinggi menunjukkan minat mahasiswa terhadap ekstrakurikuler futsal sangat tinggi, karena sejak awal mahasiswa sudah mempunyai minat yang sangat tinggi 
baik terhadap pembina/ pelatihnya dengan cara memberikan materi latihan yang menyenangkan sehingga rata-rata mahasiswa mempunyai perasaan sangat senang saat mengikuti ekstrakurikuler futsal. Hal ini juga ditunjukan dengan tingginya rata-rata kemauan mahasiswa dalam mengikuti ekstrakurkuler sangat tinggi. Sehingga rata-rata para mahasiswa yang mengikuti ekstrakurikuler futsal mempunyai rasa sosial yang sangat tinggi terhadap sesama teman. Dengan demikian dapat disimpulkan maka motivas mahasiswa dengan indikator kemauan dan sikap sosial terhadap teman sangat tinggi dalam mengikuti ekstrakurikuler futsal.

Saran bagi mahasiswa adalah sebaiknya mempertahankan minat dan motivasinya yang sudah ada, karena hampir sebagian besar mahasiswa sudah memiliki sikap dan prilaku yang baik terhadap ekstrakurikuler, baik itu sikap terhadap guru atau pelatih, perasaan senang terhadap ekstrakurikuler futsal, kemauan terhadap ekstrakurikuler futsal dan rasa sosial yang baik. Bagi guru atau pelatih saran saya adalah jangan pernah lelah mendidik dan mengajarkan kepada siswa tentang betapa pentingnya kesehatan, dan selalu memberikan inovasi-inovasi dan metode-metode terbaru dalam kegiatan belajar mengajar kegiatan ekstrakurikuler agar tujuan dari kegiatan tersebut mendapatkan hasil yang maksimal. Saran saya bagi pihak program studi adalah semoga program studi terus mendukung kepada mahasiswa terkait hal apapun yang berhubungan dengan futsal agar tujuan dari kegiatan ekstrakurikuler dapat terlaksana dengan baik dan dapat memperoleh hasil maksimal, serta terus mengembangkan sarana dan prasarana yang ada di program studi tersebut.

\section{DAFTAR RUJUKAN}

Ateng, A. K.. 1992. Asas dan Landasan Pendidikan Jasmani. Jakarta: Depdikbud

Arikunto, S. 2002. Prosedur Penelitian Pendidikan. Bandung: Angkasa

B. uno, (2008), teori motivasi dan pengukuran analisisdibidang pendidikan, Bumi aksara, jakarta

Chaplin. 2002. J. P. 2002.Kamus Psikologi. Jakarta : PT Raja Grafindo Persada

Daryanto, G. S. 1996. Teori Motivasi dan Aplikasinya. Jakarta : Rineka Cipta

Effendi. 1985. Pengantar Psikologi. Bandung : Pn.Tarsip.

Hurlock, Elisabet. B. 1993. Perkembangan Anak. Erlangga : PT. Gelora Angkasa Pratama

Halim, S. 2009 : 9. Pengertian Futsal. Erlangga: PT. Gelora Angkasa

Hamalik, oemar,2013, proses belajar mengajar $n .($ jakarta : PT.Bumi Aksara )

Iskandar, Yul. 2000. Test Bakat, Minat, Sikap dan Personiliti MMPI-DG. Jakarta: Yayasan Dharma Graha

Martin, H., (1992). Motivasi daya penggerak tingkah laku, jakarta: Rineka cipta.

Prayitno, E. (1989). Motivasi dalam belajar dan berprestasi. Jakarta : Departemen Pendidikan dan Kebudayaan Direktorat jendral pendidikan Tinggi.

Rosdiani, D. 2012. Model Pembelajaran Langsung dalam Pendidikan Jasmani dan Kesehatan. Bandung : Alphabeta.

Sardiman, 2007, interaksi dan motivasi belajar mengajar: Bandung, Rajawali Pers 